\title{
Diminished Bactericidal Capacity for Group B Streptococcus in Neutrophils from "Stressed" and Healthy Neonates
}

\author{
JOHN STROOBANT, MARY CATHERINE HARRIS, CAROLYN S. CODY, RICHARD A. POLIN, ${ }^{(31)}$ \\ AND STEVEN D. DOUGLAS \\ Divisions of Neonatology and Allergy-Immunology of The Children's Hospital of Philadelphia, The Joseph \\ Stokes Jr. Research Institute, and Department of Pediatrics of the University of Pennsylvania School of Medicine, \\ Philadelphia, Pennsylvania USA
}

\begin{abstract}
Summary
This study compared the bactericidal capacity of polymorphonuclear leukocytes (PMNs) from neonates and adults for type Ic group B Streptococcus (GBS), and examined the effect of severe stress on the bactericidal capacity of PMNs from newborn infants. PMNs were obtained from three study groups: 26 adults, 13 healthy neonates (cord blood), and 29 stressed neonates. Stress was defined as an acute respiratory illness or bacterial infection requiring assisted ventilation. Bacterial killing was assessed using a fluorochrome microassay and PMNs adherent to glass coverslips. PMNs from stressed infants killed significantly fewer GBS than PMNs from adults $(P<0.001$ at both time points). PMNs from healthy infants also demonstrated reduced killing compared with adults $(P<0.01$ at $60 \mathrm{~min} ; P<0.001$ at $90 \mathrm{~min})$. There was no significant difference in bacterial killing between stressed and healthy neonates and no correlation between bactericidal capacity and age at time of study, gestational age, birth weight, peripheral leukocyte count, or Apgar scores. Therefore, the bactericidal capacity for GBS by PMNs from neonates is diminished; however, it is not further compromised by stress.
\end{abstract}

Abbreviations

GBS, Group B Streptococcus, PMNs, polymorphonuclear leukocytes

Bacterial infection is a major cause of morbidity and mortality during the neonatal period. Although many different classes of microorganisms may be responsible for infection at this time of life, group B Streptococcus is the bacterium most often isolated $(3,9)$. The factors responsible for the increased frequency of infection are not completely understood; however, specific studies have implicated deficiencies of circulating antibody $(6,14)$, complement (7), and cellular function including PMN chemotaxis $(2,15,21)$. Investigations of neutrophil phagocytosis $(8,16$, $19)$, oxidative metabolism $(23,27)$, and bactericidal capacity $(20$, 28) during the neonatal period have produced controversial results. Stress has recently been suggested as an additional factor which may further compromise immune function $(8,14)$. Therefore, we have used a fluorochrome microassay to compare killing of GBS by neutrophils from healthy newborn infants, stressed newborn infants, and healthy adults.

\section{MATERIALS AND METHODS}

Study population. The study population consisted of 29 stressed neonates and 13 healthy neonates (Table 1) at The
Children's Hospital of Philadelphia and The Hospital of the University of Pennsylvania, and 26 healthy adult volunteers. Stress was defined as an acute respiratory illness or bacterial infection requiring assisted ventilation and included 24 infants with respiratory distress syndrome, two infants with proven sepsis, and three infants with aspiration syndromes. Blood samples $(0.5-2.5 \mathrm{ml})$ from the stressed neonates were drawn from indwelling arterial or venous catheters. Healthy neonates were studied using blood $(10 \mathrm{ml})$ obtained from doubly clamped cord segments at delivery. Venous blood samples were obtained from the adult volunteers. Parental permission for all blood samples was obtained in accordance with the requirements of the Human Investigation Committees from both hospitals. In every experiment, a healthy or a stressed neonate was studied with an adult control and on six occasions both a healthy and a stressed neonate were studied simultaneously with an adult.

Preparation of bacterial suspension. Type 1c group B Streptococcus (A909-14) was obtained from the late Dr. Rebecca Lancefield. Under sterile conditions, $5 \mathrm{ml}$ Todd-Hewitt broth was inoculated with a single loop of GBS and incubated overnight at $37^{\circ} \mathrm{C}$. On the following day, the GBS were centrifuged at $800 \times$ $g$ for $10 \mathrm{~min}$ at room temperature, washed twice, and resuspended in $0.1 \%$ gel water (Gelatin, Bloom 275, Fisher Scientific). An aliquot was removed to determine the optical density. The remaining suspension was then diluted to $8 \times 10^{6} \mathrm{GBS} / \mathrm{ml}$ in McCoy's/199 medium containing 10\% serum. Serum was obtained from a single adult donor known to have a high titer of opsonic anti-type 1c group B Streptococcal antibody (10), and frozen in aliquots at $-85^{\circ} \mathrm{C}$. The final bacterial concentration was confirmed by plating serial dilutions on blood agar and counting colonies.

Preparation of PMN monolayers. Blood samples, mixed with equal volumes of heparinized 3\% dextran (molecular weight 264,000 , Sigma Chemical Co.) in normal saline were allowed to separate by gravity in an upright syringe for $60 \mathrm{~min}$ at $37^{\circ} \mathrm{C}$. The plasma and buffy coat layers were removed and spun at $400 \times g$ for $10 \mathrm{~min}$ at $4^{\circ} \mathrm{C}$. The resulting leukocyte pellet was washed twice with $10 \mathrm{ml}$ cold sterile phosphate-buffered saline, $\mathrm{pH} 7.2$. The cells were counted in $2 \%$ acetic acid and resuspended in phosphate-buffered saline to a final concentration of $1 \times 10^{6}$ PMNs/ml. Using trypan blue, cell viability was consistently greater than $95 \%$. Aliquots of the PMN suspension $(0.2 \mathrm{ml})$ were pipetted on $15 \mathrm{~mm}$ diameter glass coverslips in a covered humidified Petri dish and incubated in $5 \% \mathrm{CO}_{2}$ for $60 \mathrm{~min}$ at $37^{\circ} \mathrm{C}$. The number of adherent PMNs was determined by staining one coverslip from each individual with Wright's solution and counting 10 random fields using $15-\mathrm{mm}^{2}$ grid under $\times 40$ magnification.

Fluorochrome assay of bacterial killing. Bacterial killing was 
assessed using a modification of a fluorochrome microassay recently developed by Pantazis and Kniker (18). Following the 60-min adherence preincubation, the PMN monolayers were washed gently in warmed $\left(37^{\circ} \mathrm{C}\right)$ Hanks' balanced salt solution and $0.1 \mathrm{ml}$ of the bacterial suspension was added to each coverslip. The preparation was incubated at $37^{\circ} \mathrm{C}$, and after 60 and 90 min two coverslips were washed in Hanks' balanced salt solution and stained for $60 \mathrm{sec}$ with 1:10,000 dilution of acridine orange (Sigma Chemical Co.). Bacterial killing was not assessed beyond 90 min because of loss of viability of the adherent PMNs after this time (18). The coverslips were washed in normal saline, inverted on glass slides and the excess liquid gently removed. The edges were sealed and the preparations examined under $\times 100$ oil immersion objective with a UV fluorescence microscope (Zeiss). Live organisms stained green or orange while dead organisms stained red. Only those organisms in the same plane of focus as the nucleus were counted. All slides were counted blindly by a single examiner. Total numbers of intracellular organisms were counted in 30 PMNs and percentage killing was calculated as: number dead organisms/number dead + alive organisms $\times 100$. There were no significant differences between study groups in the number of viable, adherent PMNs/coverslip, ingested bacteria/PMN, or bacteria to $\mathrm{PMN}$ ratios on the coverslips (Table 2).

The presence of extracellular green organisms was used to confirm the viability of the bacterial suspension. Study groups were compared using a Student's dependent $t$ test.

\section{RESULTS}

The percentage bacterial killing for the paired adult and infant samples is shown in Figures 1 and 2 along with the mean values for each study group. For all study groups, there was a significant increase in bacterial killing between the 60 and 90 min time points $(P<0.01)$. PMNs from stressed neonates demonstrated decreased bactericidal activity at both $60(P<0.001)$ and $90(P$ $<0.001$ ) min when compared with PMNs from adults (Fig. 1). Similarly, PMNs from healthy neonates killed significantly fewer GBS than PMNs from adults at $60(P<0.01)$ and $90(P<0.001)$ min (Fig. 2). There was no correlation between bactericidal activity and gestational age, birth weight, Apgar scores, peripheral leukocyte count, or age at time of study for either the stressed or healthy newborn infants. There was no significant difference in mean bactericidal capacity at either time point between PMNs from healthy and stressed infants.

\section{DISCUSSION}

This study demonstrates that PMNs from stressed and healthy neonates have decreased bactericidal activity for type Ic GBS when compared to healthy adults in the presence of $10 \%$ adult serum with a high titer of opsonic antibody, and a bacteria to PMN ratio of $8: 1$. Furthermore, there is no significant difference in bacterial killing between adherent PMNs from stressed and healthy newborn infants and no correlation between the bactericidal capacity and age of infant at the time of study, gestational age, birth weight, peripheral leukocyte count, or Apgar scores.

Investigations of PMN bactericidal capacity in neonates have produced conflicting results. Becker et al. (4) demonstrated decreased killing of type III GBS when PMNs from newborn infants were compared with those from adults using a modified classical Maaloe killing assay $(1,12,25)$ and a bacteria to cell ratio of 5

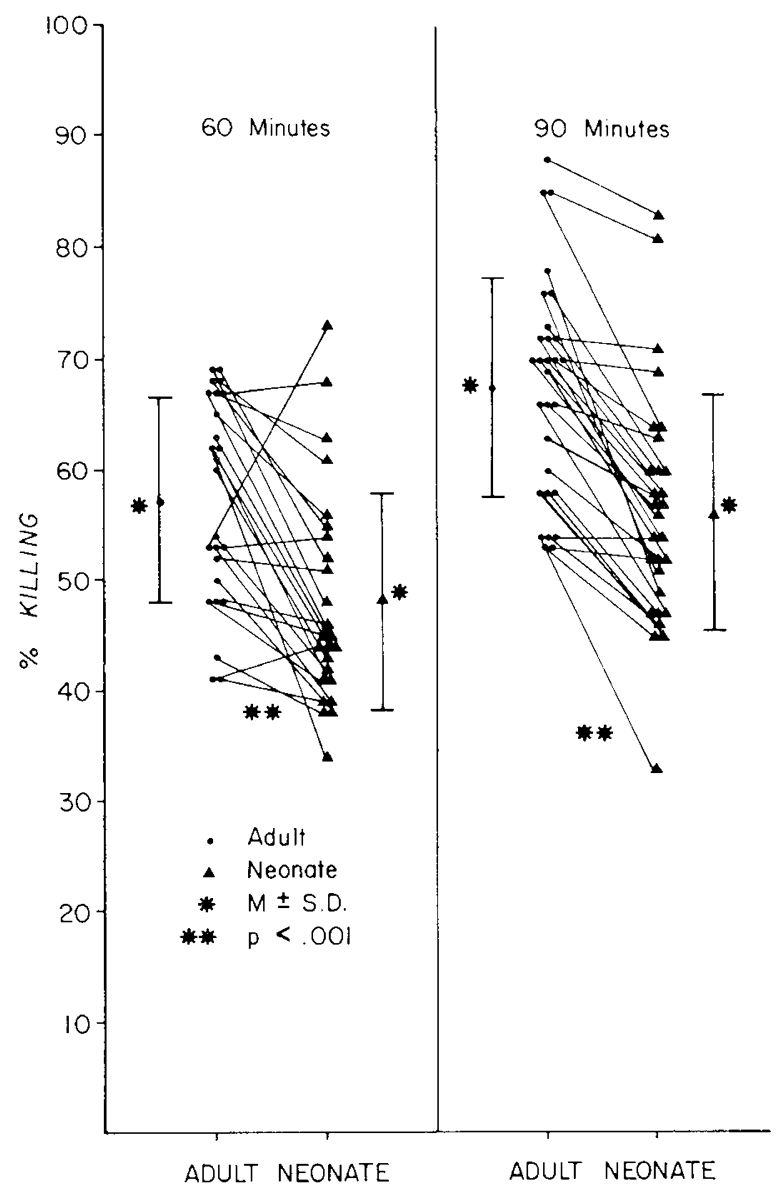

Fig. 1. Percentage killing of type Ic group B Streptococcus by PMNs from stressed neonates compared with adult controls.

Table 1. Study population*

\begin{tabular}{lcccccc}
\hline & Birthweight $(\mathrm{g})$ & $\begin{array}{c}\text { Gestational age } \\
(\text { weeks })\end{array}$ & Apgar score & $\begin{array}{c}\text { Mode of } \\
\text { delivery }\end{array}$ & $\begin{array}{c}\text { Study age } \\
(\text { days })\end{array}$ & $\begin{array}{c}\text { Leukocyte count } \\
\times 10^{-3} / \mathrm{mm}^{3}\end{array}$ \\
\hline Healthy neonates & $3239.2 \pm 208.9$ & $38.8 \pm 1.3$ & $8.1 \pm 1.0(1 \mathrm{~min})$ & $58.3 \%$ SVD & $\dagger$ & $\ddagger$ \\
$\quad(n=13)$ & $(2820-3500)$ & $(36-40)$ & $8.8 \pm 1.0(5 \mathrm{~min})$ & $46.2 \%$ ECS & & \\
"Stressed" neonates & $1935 \pm 891.1$ & $32.9 \pm 4.3$ & $4.8 \pm 3.0(1 \mathrm{~min})$ & $58.6 \%$ SVD & $3.0 \pm 3.5$ & $11.7 \pm 5.3$ \\
$(n=29)$ & $(800-3600)$ & $(25-41)$ & $6.9 \pm 2.4(5 \mathrm{~min})$ & $41.4 \% \mathrm{CS}$ & & \\
\hline
\end{tabular}

* Values are means \pm SD; SVD, spontaneous vaginal delivery; ECS, elective cesarean section; CS, cesarean section.

† Cord blood samples drawn at delivery.

$\ddagger$ Data not obtained.

Table 2. PMN adherence and GBS uptake*

\begin{tabular}{lcccc}
\hline & & \multicolumn{2}{c}{ Ingested GBS/cell } \\
\cline { 3 - 5 } & PMNs/ $\mathrm{mm}^{3} \times 10^{-3} /$ coverslip & GBS:PMN ratio & $60 \mathrm{~min}$ & $90 \mathrm{~min}$ \\
\hline Adult & $1.9 \pm 0.8$ & $7.6 \pm 6.3: 1$ & $10.0 \pm 3.7$ & $11.2 \pm 4.4$ \\
"Stressed" neonates & $1.5 \pm 0.6$ & $9.4 \pm 11.1: 1$ & $10.4 \pm 5.0$ & $11.3 \pm 4.1$ \\
Healthy neonates & $1.6 \pm 0.7$ & $7.4 \pm 5.4: 1$ & $10.1 \pm 3.6$ & $11.2 \pm 3.8$ \\
\hline
\end{tabular}

* Values are means $\pm \mathrm{SD}$. 


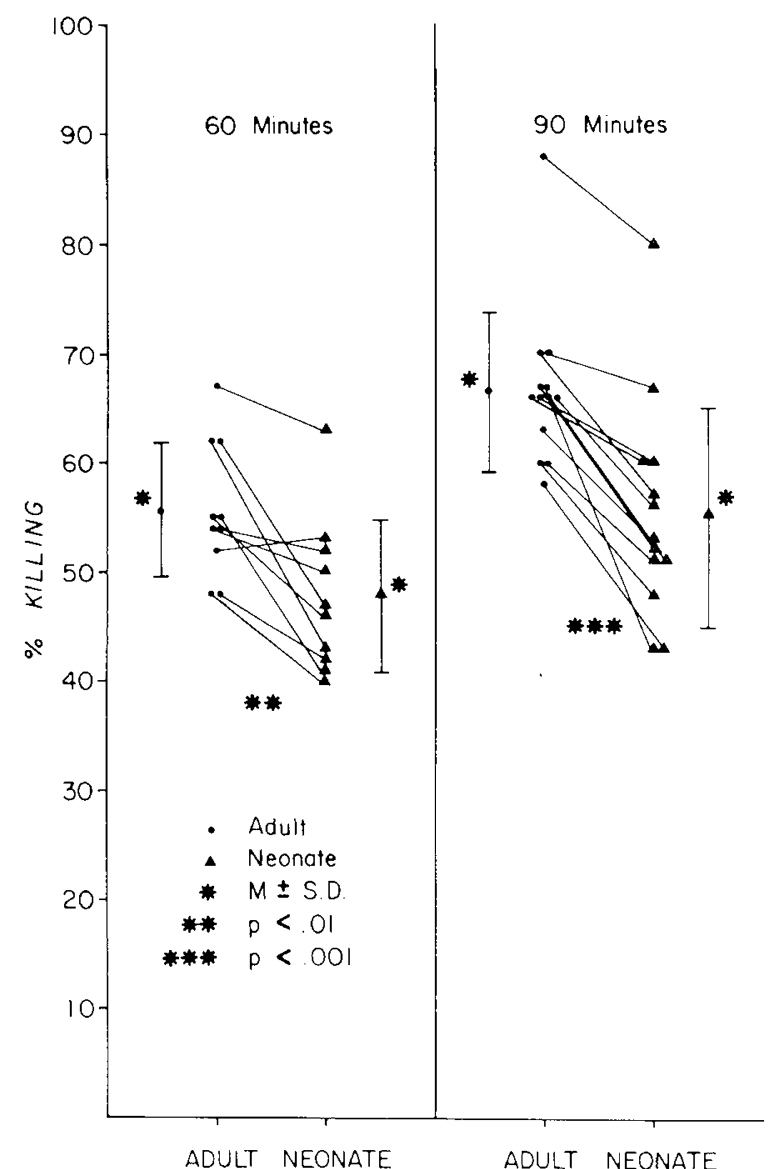

Fig. 2. Percentage killing of type Ic group B Streptococcus by PMNs from healthy neonates compared with adult controls.

10:1. In contrast, granulocytes from neonates and adults showed equivalent killing of type Ia GBS (4). Our recent preliminary experiments (unpublished) using two clinical isolates of type Ic group B Streptococcus demonstrate comparable killing by neutrophils from newborn infants and adults. These findings suggest an interstrain differential bactericidal capacity, possibly related to their biochemical differences. In this context, additional investigations with various test organisms are essential.

Mills et al. (17) also demonstrated decreased bactericidal activity when PMNs from healthy neonates were compared with their mothers and healthy adult controls using Escherichia coli and Staphylococ'us aureus at high (100:1) but not low (1:1) bacteria to PMN ratios. In contrast, Wright et al. (28) and McCracken and Eichenwald (13) reported normal killing of $S$. aureus, $E$. coli, and Pseudomonas aeruginosa by PMNs from healthy newborn infants using a classical killing assay with low bacteria to PMN ratios and pooled adult human serum.

The mechanism responsible for the deficient killing of type Ic GBS by granulocytes from newborn infants in this study is unknown. In addition, there are several aspects of the experimental design which may have influenced the study results. These include choice of the test organism (type Ic GBS) $(13,17)$, the concentration (10\%) and opsonin source (high titer adult serum) $(6,24)$, and the bacteria to PMN ratio $(7-9: 1)(17,27)$. A low bacteria to PMN ratio was specifically chosen for our study to simulate more closely the ratio which occurs during sepsis in vivo $(5,22)$. If a higher bacteria to $P M N$ ratio had been chosen, this might have provided sufficient stress to demonstrate subtle differences in PMN function between the stressed and healthy newborn infant populations. In addition, the fluorochrome microassay, as opposed to the classical killing assay, selected a population of adherent granulocytes which may have differed in bactericidal capacity from PMNs in suspension. Pre- liminary studies indicate no significant change in number of adherent PMNs during the bacterial incubations. Therefore, differences in bactericidal capacity between newborn and adult PMNs are unlikely to reflect a changing population of adherent phagocytes.

Discrepancies between the fluorochrome and modified Maaloe assays may be explained by the manner in which viable and killed organisms are identified. In the fluorochrome microassay, a change in fluorescence from green to red signifies extensive uncoiling of the DNA helix (11). In contrast, minimal alterations of DNA structure in the Maaloe method may affect the ability of the bacteria to replicate in culture $(11,26)$. Finally, the fluorochrome microassay may have underestimated the bactericidal capacity of PMNs from both adults and infants because organisms which were adherent but not yet ingested would be read as viable; however, in our test system only bacteria which were in focus with the cell nucleus were counted.

This study also examined the effect of severe stress on the bactericidal capacity of PMNs from newborn infants. Previous investigations have demonstrated decreased bactericidal activity under clinical conditions in which the stress varied from mild to severe (acidosis, sepsis, hyperbilirubinemia, respiratory distress syndrome, meconium aspiration, cesarean section, diabetic pregnancy, and intrauterine growth retardation) $(8,28)$. The current study investigated only severely stressed infants with sepsis, aspiration syndromes, or noninfectious respiratory disease, all of whom required assisted ventilation. There was no difference in bactericidal activity in neutrophils from the healthy and stressed newborn populations during the first few days of life.

In conclusion, neutrophils from newborn infants demonstrate deficient bactericidal capacity for GBS, which is not influenced by severe stress, prematurity, age, or birth weight. Among other factors, diminished capacity for bacterial killing may contribute to the increased morbidity and mortality from neonatal GBS infection.

\section{REFERENCES AND NOTES}

1. Alexander JW. Windhorst DB. Good RA 1968 Improved test for the evaluation of neutrophil function in human disease. J Lab Clin Med 72:136

2. Anderson DC, Hughes BJ. Smith CW 1981 Abnormal mobility of neonatal polymorphonuclear leukocytes. J Clin Invest 68:863

3. Baker CJ 1980 Group B streptococcal infections. Adv Intern Med 25:475

4. Becker ID, Robinson OM. Bazan TS, Lopez-Osuna M, Kretschmer RR 1981 Bactericidal capacity of newborn phagocytes against group B beta-haemolytic streptococci. Infect Immun 34:535

5. Dietzman DE. Fischer GW, Schoenknecht FD 1974 Neonatal Escherichia coli septicemia-bacterial counts in blood. J Pediatr 85:128

6. Dossett JH. Williams RC. Quie PG 1969 Studies on interaction of bacteria, serum factors and polymorphonuclear leukocytes in mothers and newborns. Pediatrics 44:49

7. Fireman P, Zuchowski DA, Taylor PM 1969 Development of human complement system. J Immunol 103:25

8. Forman ML, Stiehm ER 1969 Impaired opsonic activity but normal phagocytosis in low-birth-weight infants. N Engl J Med 281:926

9. Franciosi RA, Knostman JD, Zimmerman RA 1973 Group B streptococcal neonatal and infant infections. J Pediatr 82:707

10. Harris MC. Stroobant J. Cody CS, Douglas SD, Polin RA 1983 Phagocytosis of group B streptococ'tes by neutrophils from newborn infants. Pediatr Res 17:358

11. Kasten FH 1967 Cytochemical studies with acridine orange and the influence of dye contaminants in the staining of nucleic acids. Int Rev Cytol 21:141

12. Maaloe O 1946 On the Relation between Alexin and Opsonin. Munksgaard, Copenhagen, 1946

13. McCracken $\mathrm{GH}$. Eichenwald HF 1971 Leukocyte function and the development of opsonic and complement ac.ivity in the neonate. Am J Dis Child 121:120

14. Miller ME 1969 Phagocytosis in the newborn infant: Humoral and cellular factors. J Pediatr 74:255

15. Miller ME 1971 Chemotactic function in the human neonate: Humoral and cellular aspects. Pediatr Res 5:487

16. Miller ME 1978 Phagocytic cells. In: Oliver TK (ed): Host Defenses in the Human Neonate. Grune and Stratton, New York, pp 59-71

17. Mills EL. Thompson T, Bjorksten B, Filipovich D, Quie PG 1979 The chemiluminescence response and bactericidal activity of polymorphonuclear neutrophils from newborns and their mothers. Pediatrics $63: 429$

18. Pantazis CG. Kniker WT 1979 Assessment of blood leukocyte microbial killing by using a new fluorochrome microassay. J Reticuloendothel Soc 26:155

19. Park BH. Holmes B, Good RA 1970 Metabolic activities in leukocytes of 
newborn infants. J Pediatr 76:237

20. Quie PG, Mills EL 1979 Bactericidal and metabolic function of polymorphonuclear leukocytes. Pediatrics [suppl.] 64:719

21. Repo H, Jokipii AM, Leirisalo M, Kosunen TU 1980 Leukocyte motility in the newborn: Determination of spontaneous movement is essential in the in vitro assessment of neutrophil chemotaxis. Clin Exp Immunol 40:620

22. Santosham M. Moxon ER 1977 Detection and quantitation of bacteremia in childhood. J Pediatr 91:719

23. Shigeoka AO, Charette RP. Wyman ML, Hill HR 1981 Defective oxidative metabolic responses of neutrophils from stressed neonates. J Pediatr 98:392

24. Shigeoka AO, Santos JI, Hill HR 1979 Functional analysis of neutrophil granulocytes from healthy, infected, and stressed neonates.J Pediatr 95.454

25. Steigbigel RT, Lambert LH, Remington JS 1974 Phagocytic and bactericidal properties of normal human monocytes. J Clin Invest 53:131

26. Stroobant J, Harris MC, Cody CS, Polin RA, Douglas SD 1983 Bactericidal capacity for group B streptococci of neutrophils from children with chronic granulomatous disease. Infect Immun 39:966-969

27. Van Epps DE, Goodwin JS, Murphy S 1978 Age-dependent variations in polymorphonuclear leukocyte chemiluminescence. Infect Immun 22:57

28. Wright WC, Ank BJ, Herbert J, Stiehm ER 1975 Decreased bactericidal activity of leukocytes of stressed newborn infants. Pediatrics 56:579

29. The authors thank Dr. J. Campos for technical advice, and Barbara Erwins and Mary Swayne for editorial assistance.

30. This study was supported by The Thrasher Research Fund, the Kroc Foundation, and the National Institutes of Health, Department of Human Services Grants 1 R01 HL 27068 and 1 P01 NS 17752.

31. Requests for reprints should be addressed to: Dr. Richard A. Polin, Division of Neonatology. The Children's Hospital of Philadelphia, 34th Street and Civic Center Boulevard, Philadelphia, PA 19104-4399.

32. Received for publication September 1, 1983.

\title{
Reduction of Phagocyte Adherence by Nephritic Sera: Relation to Complement Activation
}

\author{
C. FREDERIC STRIFE(43) AND EDWARD J. RULEY \\ From the Children's Hospital Research Foundation and the Department of Pediatrics, University of Cincinnati \\ College of Medicine, Cincinnati, Ohio [C.F.S.J and Children's Hospital National Medical Center and the \\ Department of Pediatrics, George Washington School of Medicine, Washington, D.C. [E.J.R.] USA
}

\begin{abstract}
Summary
Phagocytes isolated from either normal donors or from patients with poststreptococcal (P-SGN), lupus erythematosus (SLEGN), or membranoproliferative (MPGN) glomerulonephritis showed normal adherence to glass (PAg) after incubation in normal human serum (NHS), but was reduced after incubation in patient serum. Low PAg was the consequence of incubation of normal phagocytes with the earliest available sera from all $22 \mathrm{P}$ SGN patients, 28 of 37 SLE-GN patients, 19 of 25 patients with MPGN type I, all 10 with types II and III, and all 5 with nephritis associated with chronic bacteremia. Low $\mathrm{C} 3$ and decreased PAg were related by regression analysis in sera from patients with P-SGN $(P<0.001)$, SLE-GN $(P<0.005)$, and MPGN $(P<0.001)$ type I. In patients with P-SGN and one patient with nephritis associated with chronic bacteremia, complement levels and PAg returned to normal in parallel with clinical improvement. In vitro, PAg was reduced by NHS treated with either zymosan or bovine serum albumin (BSA)-anti-BSA complexes but neither BSA-anti-BSA complexes or zymosan, previously incubated in NHS, reduced PAg. PAg was normal in serum deficient in $\mathrm{C} 4$ or $\mathrm{C} 5$ unless treated with zymosan.
\end{abstract}

\section{Abbreviations}

P-SGN, poststreptococcal glomerulonephritis SLE-GN, systemic lupus erythematosus glomerulonephritis MPGN, membranoproliferative glomerulonephritis

BSA, bovine serum albumin

NHS, normal human serum

PAg, phagocytic adherence to glass

RC4 GP, C4-deficient guinea pig serum

RC5, congenitally C5-deficient human plasma

Previous investigators have described abnormalities in the function of phagocytes (polymorphonuclear leukocytes and monocytes) obtained from the circulation of patients with a variety of glomerulonephritides. These abnormalities include: (a) decreased chemotactic responsiveness of phagocytes from patients with P-SGN, SLE-GN, MPGN, and other nephritides (5, 21, 22), (b) defective phagocytosis by cells from patients with SLE-GN $(2,23,31,32,41)$, and (c) decreased adherence to glass by both phagocytes in whole blood from patients with P-SGN (26) and monocytes incubated in serum from patients with SLEGN (31). In vitro studies of phagocytes from some of these patients suggest that the impaired cellular function results from factor(s) present in nephritic serum $(2,5,21-23,31,32,41)$ related to the complement system $(22,26)$ and that resolution of these phagocyte abnormalities may reflect lessening of disease activity $(22,26,31)$.

Phagocyte adherence has been studied using a variety of in vitro techniques which substitute negatively changed surfaces for vascular endothelium (25). Adherence of phagocytes to vascular endothelium has been shown to be prerequisite for many normal functions including diapedesis (1), response to chemotactic stimuli (3), and, in most instances, phagocytosis (39). The present study investigates the effect of serum from children with glomerulonephritis on the ability of isolated autologous or normal donor phagocytes to adhere to a negatively charged surface. These studies suggest that phagocyte adherence is reduced in the presence of nephritic serum as the result of a humoral phenomenon probably produced by generation of a factor(s) when $\mathrm{C} 3$ is activated

\section{MATERIALS AND METHODS}

Study Subjects. Control population. The control population consisted of 30 healthy adult laboratory personnel, 20 children with various nonrenal disorders, and 32 children with a variety of known renal disorders. All 82 control individuals had normal 